\title{
Opposite Modulation of Opiate Withdrawal Behaviors on Microinfusion of a Protein Kinase A Inhibitor Versus Activator into the Locus Coeruleus or Periaqueductal Gray
}

\author{
Laurie J. Punch, David W. Self, Eric J. Nestler, and Jane R. Taylor \\ Laboratory of Molecular Psychiatry, Departments of Psychiatry and Pharmacology, Yale University School of Medicine \\ and Connecticut Mental Health Center, New Haven, Connecticut 06520
}

Chronic opiate administration upregulates the cAMP pathway in the locus coeruleus (LC). This adaptation is thought to increase the electrical excitability of LC neurons and contribute to the dramatic increase in LC firing induced by opioid receptor antagonists in opiate-dependent animals. The goal of the present study was to evaluate directly a role of the cAMP pathway in opiate withdrawal behaviors by studying, in vivo, whether withdrawal is influenced by intra-LC infusion of compounds known to activate or inhibit protein kinase $A$ (PKA). Infusions into amygdala or periaqueductal gray (PAG) were studied for comparison. In one series of experiments the effect of intra-LC, intra-amygdala, or intra-PAG infusions of the PKA inhibitor Rp-cAMPS on naloxone-precipitated withdrawal from morphine was examined. Intra-LC infusions of Rp-cAMPS significantly attenuated several prominent behavioral signs of morphine withdrawal. Intra-PAG infusions of Rp-cAMPS also significantly attenuated opiate withdrawal behaviors, although different behaviors were affected. In contrast, intra-amygdala infusions of Rp-cAMPS were without significant effect. In a second series of experiments the effect of intra-LC or intra-PAG infusions of the PKA activator Sp-cAMPS on behavior in nondependent drug-naive animals was determined. Sp-cAMPS infusions into either brain region induced a quasi-withdrawal syndrome, but the observed behaviors differed between the two groups. Analysis of the phosphorylation state of tyrosine hydroxylase, a well characterized substrate for PKA, confirmed the ability of Rp-cAMPS and Sp-cAMPS to inhibit and activate, respectively, PKA activity in vivo. Together, these data provide direct evidence for involvement of the cAMP-PKA system in the LC, as well as in the PAG, in opiate withdrawal and withdrawalrelated behaviors.

Key words: morphine; opiate dependence; cAMP; protein phosphorylation; amygdala; periaqueductal gray
Activation of the locus coeruleus (LC), the major noradrenergic nucleus in brain, is thought to play an important role in physical opiate withdrawal. Microinjection of opioid receptor antagonists into the LC elicits the greatest degree of withdrawal behaviors in opiate-dependent animals, even when compared with withdrawal behaviors produced by intracerebroventricular antagonist administration (Koob et al., 1992; Maldonado et al., 1992). Moreover, lesions of the LC or pharmacological inhibition of LC firing rates attentuates the severity of antagonist-precipitated opiate withdrawal (Taylor et al., 1988, 1997; Maldonado and Koob, 1993).

Although activation of LC neurons elicited on withdrawal is mediated in part by increased glutamatergic transmission to the LC (Rasmussen and Aghajanian, 1989; Akaoka and Aston-Jones, 1991; Rasmussen et al., 1995), there is also evidence that upregulation of the cAMP pathway in LC neurons contributes to this phenomenon (Nestler, 1992, 1996). Thus, chronic morphine administration increases levels of adenylyl cyclase and protein kinase A (PKA) in the LC (Duman et al., 1988; Nestler and Tallman, 1988; Matzuoka et al., 1994). These adaptations have

\footnotetext{
Received June 6, 1997; revised Aug. 8, 1997; accepted Aug. 14, 1997.

This work was supported by United States Public Health Service Grants DA08227 and DA00203 and by the Abraham Ribicoff Research Facilities of the Connecticut Mental Health Center, State of Connecticut Department of Mental Health and Addiction Services. We thank Valyphone Phantharangsy and Sarah Lane-Ladd for their excellent technical assistance.

Correspondence should be addressed to Dr. Jane R. Taylor, Department of Psychiatry, Yale University School of Medicine, SHM B227, 333 Cedar Street, New Haven, CT 06520.

Copyright (C) 1997 Society for Neuroscience $\quad 0270-6474 / 97 / 178520-08 \$ 05.00 / 0$
}

been shown to increase the electrical excitability of LC neurons (Alreja et al., 1991; Kogan et al., 1992; Shiekhattar and AstonJones, 1993) and appear to contribute to activation of the LC seen on precipitation of withdrawal (Rasmussen et al., 1990; Kogan et al., 1992).

However, direct evidence linking the cAMP pathway in the LC to behavioral signs of withdrawal has been lacking. Intracerebroventricular or intra-LC administration of $\mathrm{H}-7$ or $\mathrm{H}-8$, which inhibits several protein kinases, including PKA, has been shown to attenuate behavioral signs of opiate withdrawal (Maldonado et al., 1995; Tokuyama et al., 1995). Recently, Maldonado et al. (1996) reported an attenuation of withdrawal in mice deficient in the transcription factor CREB (cAMP response element binding protein). A similar reduction in withdrawal is seen after a selective reduction in CREB levels in the LC, achieved by intra-LC administration of CREB antisense oligonucleotide (Lane-Ladd et al., 1997). Given the important role of PKA in controlling CREB function, these findings are consistent with the involvement of the cAMP pathway in long-term responses to opiates. Nevertheless, these earlier studies have not related PKA function in the LC specifically to opiate withdrawal.

The aim of this study was to address this question directly by determining the behavioral effects of administering specific activators or inhibitors of PKA into the LC. We also compared the effects of intra-LC infusions to infusions into two other brain regions implicated in physical opiate withdrawal: amygdala (Lagowska et al., 1978; Calvino et al., 1979; Maldonado et al., 1992; Matsuoka et al., 1994) and periaqueductal gray (PAG) 
(Cools et al., 1983; Maldonado et al., 1992). Two cAMP analogs were used: Rp-cAMPS and its stereoisomer, Sp-cAMPS (Gjertsen et al., 1995). Rp-cAMPS is a highly specific PKA inhibitor; it blocks the ability of endogenous cAMP to activate the enzyme. Rp-cAMPS has been shown to prevent the excitation of LC neurons in response to activation of the cAMP pathway (Shiekhattar and Aston-Jones, 1993). In contrast, Sp-cAMPS is a highly specific PKA activator; it mimics the actions of endogenous cAMP. We show here that intra-LC infusion of Rp-cAMPS attentuates opiate withdrawal behaviors in opiate-dependent rats, whereas intra-LC infusion of Sp-cAMPS elicits some withdrawallike behaviors in opiate-naive rats. Similar results were obtained for intra-PAG, but not intra-amygdala, infusions. These results provide direct evidence that neuroadaptations in the cAMP pathway in the LC and certain other brain regions in response to chronic opiate exposure contribute to behavioral manifestations of opiate withdrawal.

\section{MATERIALS AND METHODS}

Animals. Male Sprague-Dawley rats (Camm, Wayne, NJ), which weighed $\sim 275-300 \mathrm{gm}$ at the start of the experiment, were used. They were housed in groups of two in plastic cages over pans containing Beta chips. Food and water were continuously available. Animals were maintained on a 12:12 hr light/dark cycle. Plastic boxes $(37 \times 28 \times 29 \mathrm{~cm})$ were used as test chambers. They were separated into quadrants with markings so that activity could be measured by counting crossings of a section. A layer of Beta chips served as bedding.

Drug treatments. Morphine treatment, and precipitation of withdrawal, was performed according to published procedures (Taylor et al., 1988). Morphine pellets (containing $75 \mathrm{mg}$ of morphine base; National Institute on Drug Abuse, Bethesda, MD) were implanted under light halothane anesthesia subcutaneously into the animals' back. The wounds were cleaned with antiseptic solution and closed with a stainless-steel skin clip. Animals received three pellets before the test day (day 1, one pellet; day 4, one pellet; day 5, one pellet; day 6, test). Rp-cAMPS or Sp-cAMPS (BioLog, Life Sciences Institute, Bremen, Germany) was infused at 40 $\mathrm{nmol} / 0.5 \mu \mathrm{l}$ in sterile saline or sterile PBS bilaterally into the LC, amygdala, or PAG. These doses were based on preliminary tests that were done in several animals that were not scored formally. Opiate withdrawal was precipitated by a subcutaneous injection of $1 \mathrm{mg} / \mathrm{kg}$ naloxone hydrochloride (Endo Labs, New York, NY). In addition, pilot studies with Sp-cAMPS were used to define behaviors that were modified as compared with standard withdrawal behaviors.

Intracranial surgical procedures. Stereotaxic surgery was conducted under Equithesin (4.32 mg/kg, i.p.) anesthesia (mixture of sodium pentobarbital and chloral hydrate). Animals were implanted bilaterally with stainless-steel guide cannulae (23 gauge) aimed to give access to the LC [anterior-posterior (AP) $-0.3 \mathrm{~mm}$ from lambda, from Lateral (Lat) \pm $1.2 \mathrm{~mm}$, Vertical (Vert) $5.0 \mathrm{~mm}$ from dura], the amygdala (AP $-2.3 \mathrm{~mm}$ from bregma, Lat $\pm 4.0 \mathrm{~mm}$, Vert $6.0 \mathrm{~mm}$ from dura), or the border between the PAG and deep layers of the superior colliculus (AP -7.3 $\mathrm{mm}$ from bregma, Lat $\pm 1.2 \mathrm{~mm}$, Vert $4.0 \mathrm{~mm}$ from dura), termed here the PAG. Stereotaxic coordinates were determined from Paxinos and Watson (1982). After surgery, stylettes flush with the guide cannulae were inserted into the guide cannulae to keep the tubing patent.

Intracerebral infusions were made bilaterally. Rats were hand-held while 31 gauge injection needles were placed into the surgically implanted guide cannulae. The injection needles protruded $2.0 \mathrm{~mm}$ beneath the guide cannulae and terminated in the dorsal portion of the LC (7.0 $\mathrm{mm}$ from dura), amygdala ( $8.0 \mathrm{~mm}$ from dura), or the PAG $(6.0 \mathrm{~mm}$ from dura). The injection needles were attached to syringes (Hamilton $10 \mu \mathrm{l}$ ) by PE20 tubing filled with the drug or vehicle solution. The volume infused bilaterally was $0.5 \mu \mathrm{l}$ delivered over a $2 \mathrm{~min}$ period. After the infusion a further 2 min was allowed to elapse before the injection needles were removed.

Behavioral ratings and analyses. Behavioral ratings were calculated over a $15 \mathrm{~min}$ period in a quiet, temperature-maintained $\left(68^{\circ} \mathrm{F}\right)$ room by one observer who did not know what experimental treatment had been administered. The scored signs, defined in Table 1, are based on published criteria (Taylor et al., 1988) as modified from those described by Blasig et al. (1973). The presence of each checked sign and the frequency

\begin{tabular}{|c|c|}
\hline \multicolumn{2}{|l|}{ Counted signs } \\
\hline Activity & Crossing of a quadrant mark \\
\hline Rearing & Lifting the forepaws off the ground \\
\hline Teeth chattering & $\begin{array}{l}\text { Teeth grinding or rapidly opening-clos- } \\
\text { ing of jaws }\end{array}$ \\
\hline Shake & $\begin{array}{l}\text { Shaking of the head only or rest of body } \\
\text { (wet-dog shake) }\end{array}$ \\
\hline Grooming & $\begin{array}{l}\text { Using limbs to manipulate the head or } \\
\text { body }\end{array}$ \\
\hline Jumping & Raising all limbs off the ground rapidly \\
\hline Digging & $\begin{array}{l}\text { Using the forepaws to displace the bed- } \\
\text { ding }\end{array}$ \\
\hline Freezing & Immobility for $>10 \mathrm{sec}$ \\
\hline Hopping & $\begin{array}{l}\text { Sudden lurch forward often accompanied } \\
\text { by a vocalization }\end{array}$ \\
\hline Rubbing & $\begin{array}{l}\text { Moving the jaw or the torso on the } \\
\text { ground }\end{array}$ \\
\hline
\end{tabular}

Checked signs

\begin{tabular}{|c|c|}
\hline Diarrhea & Watery feces \\
\hline Ptosis & Squinting of the eyes \\
\hline Irritability & $\begin{array}{l}\text { Vocalization when placed into or out of } \\
\text { the test box }\end{array}$ \\
\hline Lacrimation & $\begin{array}{l}\text { Appearance of a brown excretion from } \\
\text { the eyes }\end{array}$ \\
\hline Rhinorrhea & $\begin{array}{l}\text { Appearance of a brown excretion from } \\
\text { the nose }\end{array}$ \\
\hline Abnormal posture & $\begin{array}{l}\text { Lying on the side; writhing or hunching } \\
\text { of body }\end{array}$ \\
\hline Penile erection & Evidence of protrusion of the penis \\
\hline Explosive running & $\begin{array}{l}\text { Extreme horizontal and vertical locomo- } \\
\text { tor activity }\end{array}$ \\
\hline
\end{tabular}

(number) of each counted sign were noted on the score sheet. Checked signs were examined qualitatively, as a proportion of subjects showing the sign during the test, and quantitatively, as all the checked signs combined (total of seven). Counted signs were examined quantitatively as the frequency of the sign was observed. The amount of weight the animal lost during the period was analyzed also. Additional behaviors (hops, head shakes, and jumps) were determined from pilot studies, using a range of drug doses.

The mean frequency of each of the counted signs, total checked signs, and the average weight lost was evaluated using ANOVA and post hoc comparisons when multiple groups were analyzed to determine differences between treatment groups (Scheffe's $F$ test). When comparisons were made on rated behavior, the $\chi^{2}$ test was used as the nonparametric test.

Histological analysis. At the completion of the behavioral testing, histological analyses were performed. Brain sections were cut $(60 \mu \mathrm{m})$ and mounted, using standard procedures (Wolf, 1971). When the sections were examined to determine the location of the injection site, the observer was blind to the experimental treatment. Animals with inf usion sites that were determined to be outside the border of the LC, amygdala or outside an area defined as between the deep layers of the superior colliculus and PAG, animals with gross histological damage (evidence of severe cell loss or gliosis), or animals that received a unilateral infusion because of a blocked cannula were excluded from subsequent analyses.

Experiment 1. Effect of Rp-cAMPS in the LC and amygdala on naloxoneprecipitated withdrawal. Animals were habituated first to the test environment and received chronic opiate treatment via morphine pellets as described above. On the test day the animals were injected intraperitoneally with either saline or naloxone and received bilateral intra-LC or intra-amygdala infusions of Rp-cAMPS ( $40 \mathrm{nmol} / 0.5 \mu \mathrm{l}$ per side) or of 
saline. This resulted in a total of four test groups. Intracerebral inf usions were made $15 \mathrm{~min}$ before injections of naloxone; behavioral ratings were initiated $5 \mathrm{~min}$ later and lasted for $15 \mathrm{~min}$. After testing, the animals were decapitated, and the brains were placed in ice-cold saline. The brains were stored in formalin for at least 2 weeks before histological analysis.

Experiment 2. Effect of Rp-cAMPS in the PAG on naloxone-precipitated withdrawal. Procedures were identical to those of Experiment 1 except that intra-PAG infusions of Rp-cAMPS ( 20 or $40 \mathrm{nmol} / 0.5 \mu \mathrm{l}$ per side) or PBS were used.

Experiment 3. Effect of Sp-cAMPS in the LC and PAG on behavior in opiate-naive animals. Procedures were identical to those of Experiment 1 except that Sp-cAMPS (40 nmol $/ 0.5 \mu \mathrm{l}$ per side) or PBS was inf used into the LC or PAG. In addition, animals were not treated with morphine or naloxone; they received sham treatments.

Phosphorylation assays. The effect of Rp-cAMPS and Sp-cAMPS on PKA activity in the LC in vivo was assessed directly by measuring the phosphorylation state of tyrosine hydroxylase, a well characterized substrate for PKA in LC neurons (Guitart et al., 1990). Briefly, drug-naive rats received unilateral intra-LC infusions of Sp-cAMPS, or opiatedependent rats received unilateral intra-LC infusions of Rp-cAMPS followed by systemic naloxone injections, using drug regimens described in Experiments 1 and 3 above. The contralateral LCs were inf used with PBS vehicle. Rats were decapitated $30 \mathrm{~min}$ after the Rp-cAMPS or Sp-cAMPS infusions, and individual LC nuclei, obtained as 14 gauge punches from 1-mm-thick coronal brain sections, were subjected to back phosphorylation exactly as described (Guitart et al., 1990). In this procedure, acid extracts of LC are back-phosphorylated by purified PKA in the presence of $\gamma_{-}{ }^{32} \mathrm{P}[\mathrm{ATP}]$. Tyrosine hydroxylase is immunoprecipitated from the back-phosphorylated extracts by the use of a rabbit anti-tyrosine hydroxylase antiserum (kindly provided by J. Haycock, Louisiana State University, New Orleans, LA) and by fixed Staphylococcus aureus cells that possess protein A. Finally, immunoprecipitates are subjected to SDS-polyacrylamide gel electrophoresis and autoradiography. Levels of tyrosine hydroxylase back phosphorylation were quantified by a Macintosh-based image analysis system with National Institutes of Health software and calibrated to a gray scale to ensure optical density readings that varied linearly with ${ }^{32} \mathrm{P}$ incorporation. Levels of tyrosine hydroxylase back phosphorylation in injected LCs were compared with those of the contralateral, control side.

\section{RESULTS}

\section{Histological analyses}

Representative regions considered to be within the boundaries of the LC, amygdala, and area of PAG are depicted in Figure 1. Animals with deviations from these target areas, or with unilateral infusions because of blocked cannulae, were omitted from further analysis (see Materials and Methods).

\section{Behavioral analyses}

\section{Experiment 1. Effect of Rp-cAMPS in the LC and amygdala} on naloxone-precipitated withdrawal

As a first step in evaluating the role of the cAMP pathway in the LC in opiate withdrawal, we infused the PKA inhibitor, RpcAMPS, directly into the LC just before precipitation of withdrawal by naloxone administration. As depicted in Figure 2, it was found that bilateral intra-LC infusions of Rp-cAMPS (40 nmol/ $0.5 \mu$ l per side) considerably attenuated opiate withdrawal behaviors. Significant attenuation was seen for checked signs $\left(F_{(1,18)}=\right.$ $6.26 ; p<0.02)$, counted signs $\left(F_{(1,18)}=4.66 ; p<0.05\right)$, teeth chattering $\left(F_{(1,18)}=4.14 ; p=0.05\right)$, wet-dog shakes $\left(F_{(1,18)}=\right.$ $20.48 ; p<0.001)$, and total signs $\left(F_{(1,18}=15.38 ; p<0.001\right)$. With respect to the attenuation seen overall in checked signs, diarrhea and irritability alone were lowered significantly $(p<0.05)$. Weight loss also tended to be reduced by intra-LC infusions of Rp-cAMPS. Although this effect did not achieve statistical significance, the lowering of checked signs from five to three reflected this decrease in weight loss, as well as the other significantly attenuated signs.

One of the most robust effects of intra-LC infusions of Rp-

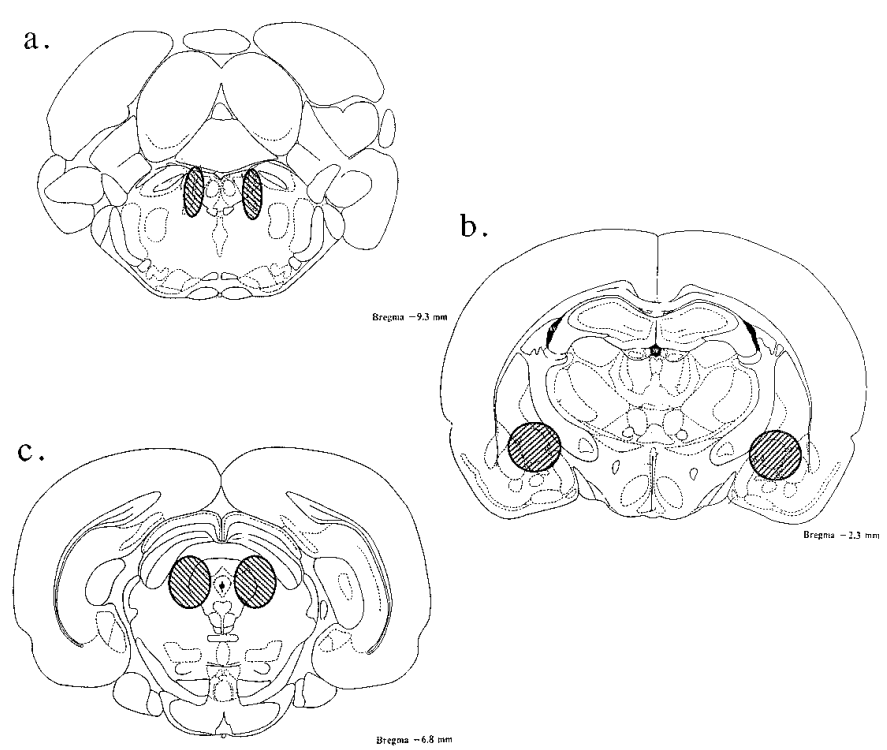

Figure 1. Representative locations of intra-LC, intra-amygdala, and intra-PAG injections used in this study. Shown are brain sections modified from Paxinos and Watson (1982) indicating the regions where the bilateral injection tips were determined to be within the intended site. $a, \mathrm{LC}$, $0.3 \mathrm{~mm}$ from lambda; $b$, amygdala, $-2.3 \mathrm{~mm}$ from bregma; and $c$, PAG, $-7.3 \mathrm{~mm}$ from bregma. All infusion tip sites were estimated from histological analysis.

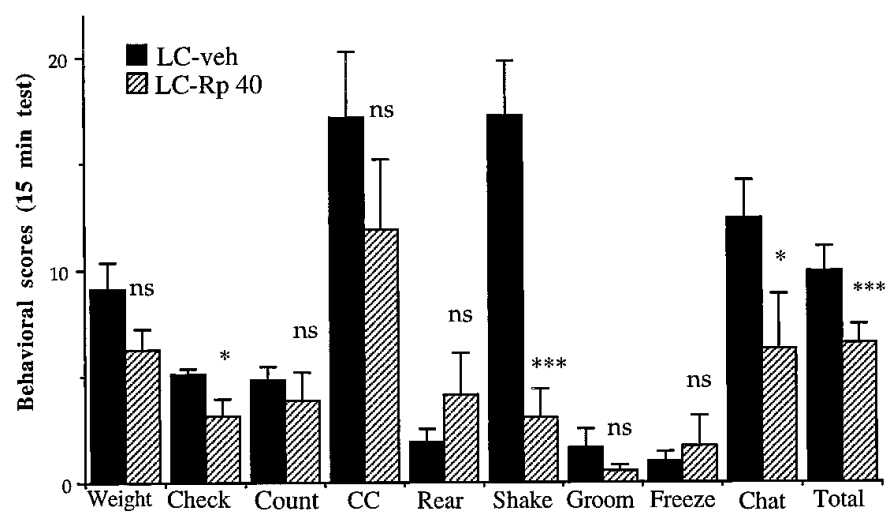

Figure 2. Effect of intra-LC infusion of Rp-cAMPS on naloxoneprecipitated withdrawal in morphine-dependent rats. Rats received bilateral infusions of Rp-cAMPS ( $40 \mathrm{nmol} / 0.5 \mu \mathrm{l}$ per side; $n=9)$ or saline $(0.5$ $\mu l$ per side; $n=11)$. Data are expressed as mean values of opiate withdrawal behaviors \pm SEM during the 15 min test period (see Materials and Methods). Weight, weight loss; Check, checked signs; Count, counted signs; CC, cross-cage activity; Rear, lifting forepaws; Shake, wet-dog shakes; Groom, grooming bouts; Freeze, freezing bouts; Chat, teeth chattering and grinding; Total, total checked and counted signs. Statistically different from saline $\left({ }^{*} p<0.05 ;{ }^{*} p<0.01 ; * * *<0.001\right) ; n s=$ not significant.

cAMPS was observed for wet-dog shakes. Naloxone-precipitated withdrawal elicited an average of 17 wet-dog shakes during the test session in the saline-infused group, whereas in animals infused with Rp-cAMPS an average of three wet-dog shakes was seen (Fig. 2). In contrast, several behaviors that would reflect generalized motor impairments, such as cross-cage activity, rearing, and freezing, were not affected by intra-LC Rp-cAMPS inf usions (Fig. 2).

In contrast to results obtained for the LC, bilateral intraamygdala inf usions of Rp-cAMPS ( $40 \mathrm{nmol} / 0.5 \mu$ l per side $)$ failed 


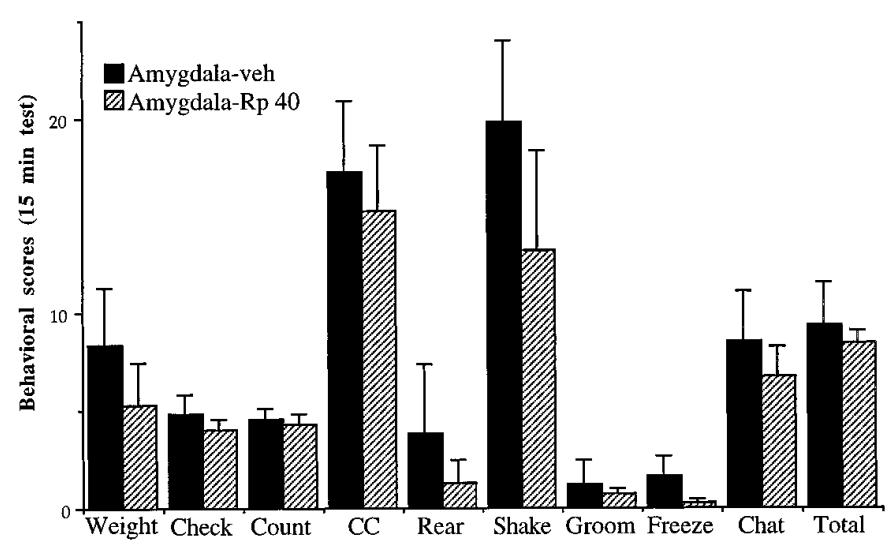

Figure 3. Effect of intra-amygdala infusion of Rp-cAMPS on naloxoneprecipitated withdrawal in morphine-dependent rats. Rats received bilateral inf usions of Rp-cAMPS ( $40 \mathrm{nmol} / 0.5 \mu \mathrm{l}$ per side; $n=4)$ or saline $(0.5$ $\mu$ l per side; $n=5$ ). Data are expressed as mean values of opiate withdrawal behaviors \pm SEM during the 15 min test period (see Materials and Methods). All other abbreviations are defined in the legend to Figure 2. There were no significant differences between the Rp-cAMPS and saline groups.

to alter opiate withdrawal behaviors (Fig. 3) and did not elicit any other discernible behavioral effects during the test session. The only trend was for a reduction in wet-dog shakes during withdrawal, but this effect was not statistically significant. In addition, no difference was observed in the severity of opiate withdrawal behaviors in animals that received intra-LC, as compared with intra-amygdala, infusions of saline vehicle (data not shown).

\section{Experiment 2. Effect of Rp-cAMPS in the PAG on} naloxone-precipitated withdrawal

We next studied the behavioral effects of infusions of Rp-cAMPS (20 or $40 \mathrm{nmol} / 0.5 \mu \mathrm{l}$ per side) into the PAG on naloxoneprecipitated withdrawal, based on previous work that has implicated this brain region in opiate action (see introductory remarks). As shown in Figure 4, the higher dose of Rp-cAMPS produced significant reductions in several withdrawal behaviors, including weight loss, wet-dog shakes, teeth chattering, checked signs, counted signs, and total signs, as compared with vehicletreated animals. In fact, no wet-dog shakes or teeth chattering was observed in any of the animals in the Rp-cAMPS-treated group, In contrast, the lower dose of Rp-cAMPS had no significant effect on withdrawal behaviors. Overall, differences were observed between the three groups for weight $\left(F_{(2,15)}=7.74 ; p<0.01\right)$, wet dog shakes $\left(F_{(2,15)}=3.43 ; p=0.05\right)$, teeth chattering and grind$\operatorname{ing}\left(F_{(2,15)}=4.48 ; p<0.05\right)$, checked signs $\left(F_{(2,15)}=12.39 ; p<\right.$ $0.001)$, counted signs $\left(F_{(2,15)}=7.04 ; p<0.01\right)$, and total signs $\left(F_{(2,15)}=14.67 ; p<0.001\right)$.

\section{Experiment 3. Effect of Sp-cAMPS in the LC and PAG on behavior in opiate-naive animals}

To follow up the observation that intra-LC infusions of RpcAMPS attenuated withdrawal signs, we studied the behavioral effect of intra-LC infusions of the PKA activator, Sp-cAMPS, in opiate-naive animals. As shown in Figure 5, it was found that bilateral intra-LC infusions of Sp-cAMPS (40 nmol/0.5 $\mu \mathrm{l}$ per side) produced several withdrawal-like behaviors (in the absence of morphine and naloxone exposure) when compared with animals that received bilateral intra-LC infusions of PBS vehicle. The behaviors that were increased significantly $(p<0.05)$ in-

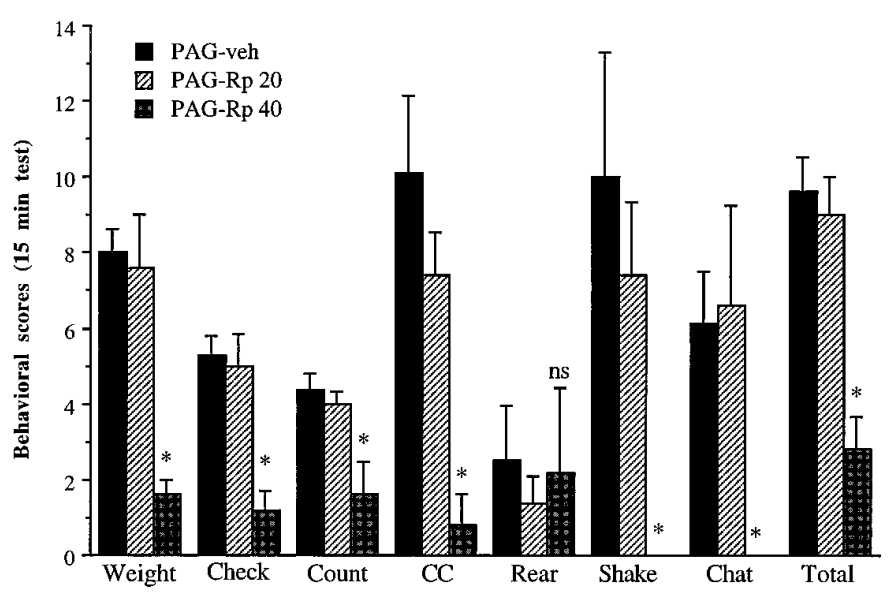

Figure 4. Effect of intra-PAG infusion of Rp-cAMPS on naloxoneprecipitated withdrawal in morphine-dependent rats. Rats received bilateral infusions of Rp-cAMPS (20 nmol/0.5 $\mu \mathrm{l}$ per side, $n=5$; or 40 $\mathrm{nmol} / 0.5 \mu \mathrm{l}$ per side, $\mathrm{n}=5)$ or $\operatorname{PBS}(0.5 \mu \mathrm{l}$ per side; $n=8)$. Data are expressed as mean values of opiate withdrawal behaviors \pm SEM during the 15 min test period (see Materials and Methods). All other abbreviations are defined in the legend to Figure 2. Statistically different from PBS $\left({ }^{*} p<0.05\right) ; n s=$ not significant.

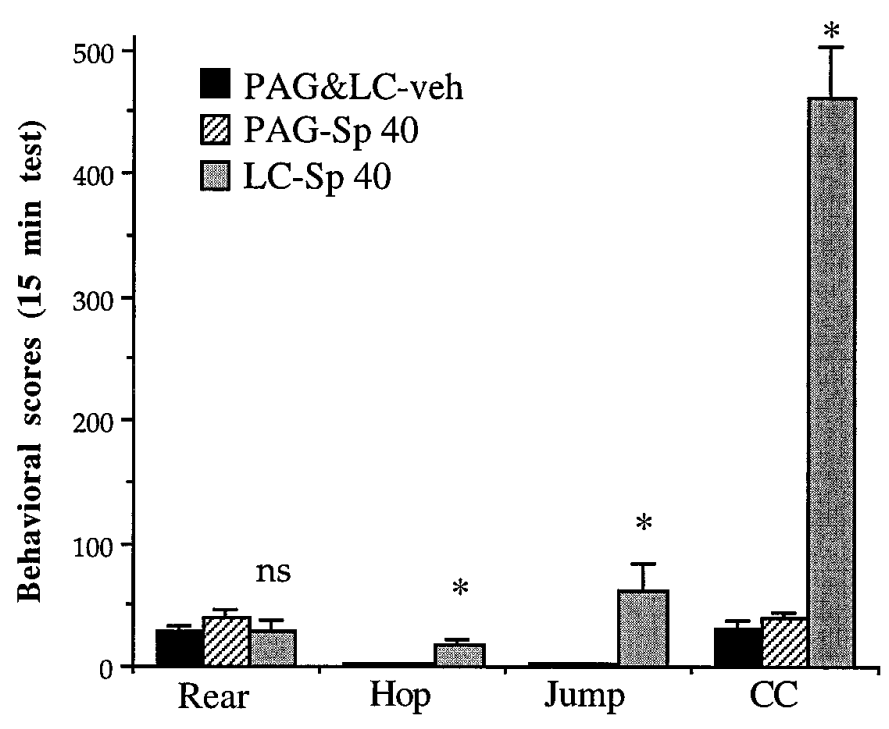

Figure 5. Effect of intra-LC infusion of Sp-cAMPS in opiate-naive animals. Rats received bilateral infusions of Sp-cAMPS (40 nmol/0.5 $\mu \mathrm{l}$ per side) into the LC $(n=4)$ or PAG $(n=6)$ or PBS $(0.5 \mu l$ per side $)$ into the LC $(n=4)$ or the PAG $(n=5)$. Because PBS infusions into the LC and PAG yielded equivalent results, data from these two groups were combined. Data are expressed as mean values of behaviors \pm SEM during the 15 min test period (see Materials and Methods). See legend to Figure 2 for definition of abbreviations. Statistically different from PBS $(* p<$ $0.05) ; n s=$ not significant.

cluded motor activity, jumping, and hopping as well as lacrimation, piloerection, and penile erection.

Given the lack of effect of intra-amygdala Rp-cAMPS on opiate withdrawal in the previous experiment and the attenuation of withdrawal seen with intra-PAG infusions of Rp-cAMPS, we decided in the current experiment to compare intra-LC infusions of Sp-cAMPS with infusions into the PAG. Intra-PAG infusions of Sp-cAMPS (40 nmol/0.5 $\mu \mathrm{l}$ per side) also produced behaviors resembling naloxone-precipitated opiate withdrawal, although, in general, different behaviors were produced by intra-PAG as com- 


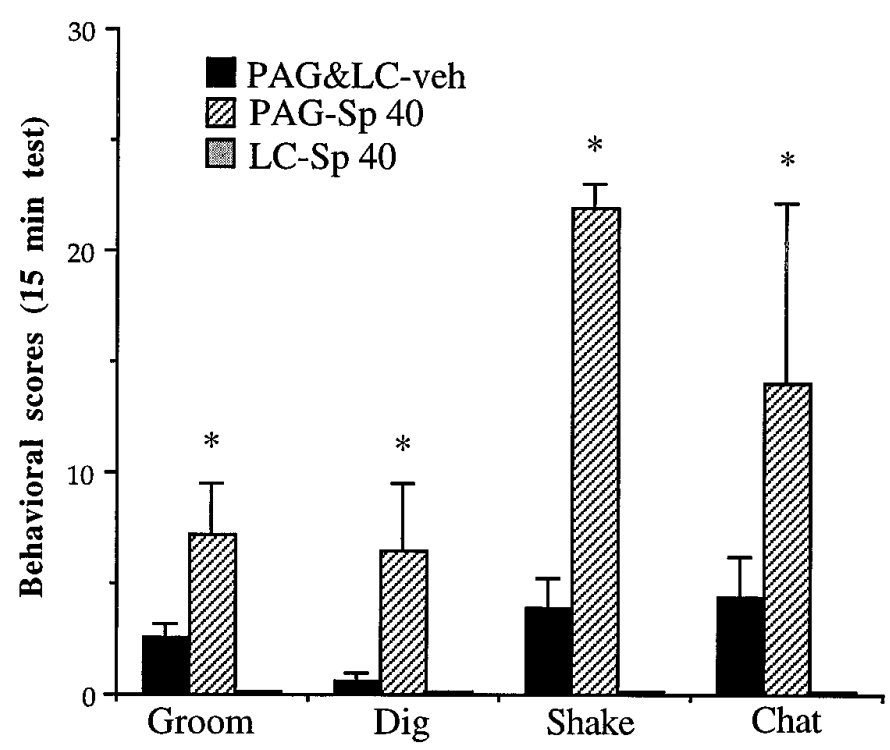

Figure 6. Effect of intra-PAG infusion of Sp-cAMPS in opiate-naive animals. Rats received bilateral infusions of Sp-cAMPS (40 nmol/0.5 $\mu \mathrm{l}$ per side $)$ into the PAG $(n=6)$ or LC $(n=4)$ or PBS $(0.5 \mu$ per side $)$ into the LC $(n=4)$ or the PAG $(n=5)$. Because PBS infusions into the LC and PAG yielded equivalent results, data from these two groups were combined. Data are expressed as mean values of behaviors \pm SEM during the 15 min test period (see Materials and Methods). Shake, Head shakes. All other abbreviations are defined in the legend to Figure 2 . Statistically different from PBS $(* p<0.05) ; n s=$ not significant.

pared with intra-LC infusions (Fig. 6). Thus, the most dramatic behaviors seen with intra-PAG infusions included head shakes, teeth chattering, grooming, digging, irritability, and diarrhea. In contrast, there was no difference in the behavioral effects of PBS vehicle when it was infused into the LC as compared with the PAG (not shown).

Overall, there were clear differences among the three groups (intra-LC Sp-cAMPS, intra-PAG Sp-cAMPS, and the two vehicle-infused groups that were combined) for counted signs $\left(F_{(2,16)}=3.81 ; p<0.05\right)$, checked signs $\left(F_{(2,16)}=10.96 ; p<\right.$ $0.001)$, and total signs $\left(F_{(2,16)}=7.08 ; p<0.01\right)$. In addition, there were differences among the three groups for hopping $\left(F_{(2,16)}=\right.$ $8.81 ; p<0.01)$, jumping $\left(F_{(2,16)}=8.32 ; p<0.01\right)$, activity $\left(F_{(2,16)}\right.$ $=44.80 ; p<0.001)$, grooming $\left(F_{(2,16)}=10.90 ; p<0.01\right)$, digging $\left(F_{(2,16)}=8.43 ; p<0.01\right)$, head shakes $\left(F_{(2,16)}=67.64 ; p<0.001\right)$, and teeth chattering and grinding $\left(F_{(2,16)}=3.66 ; p<0.05\right)$. Head shakes were increased dramatically from means of $<5$ in the intra-LC Sp-cAMPS and control groups to $>20$ in the intra-PAG Sp-cAMPS group. Head shakes were similar to wet-dog shakes seen after naloxone-precipitated withdrawal, except that they were confined to the head rather than head and body and there was no loss of balance. Hopping, in the intra-LC Sp-cAMPS group, consisted of lurches forward and often were accompanied by vocalization. This behavior was absent from the behavioral repertoire seen in the intra-PAG Sp-cAMPS and control groups. Cross-cage activity refers to the normative pattern of circling the cage and is interspersed with rearing. As shown in Figure 5, although normal levels of rearing were observed in the intra-LC Sp-cAMPS group, there was a dramatic increase in cross-cage activity: the activity rates of the animals were 10 times greater in LC-treated than in PAG-treated or vehicle-treated rats.

\section{Biochemical analyses}

To confirm that intracerebral infusions of Rp-cAMPS and SpcAMPS were effective at inhibiting and stimulating, respectively, PKA activity in vivo, we measured the effect of these agents on the state of phosphorylation of tyrosine hydroxylase in the LC. Tyrosine hydroxylase is the rate-limiting enzyme in catecholamine biosynthesis and a well characterized substrate for PKA in LC neurons (see Guitart et al., 1990). A set of opiate-naive rats received unilateral intra-LC infusions of Sp-cAMPS (40 nmol in 0.5 $\mu l)$. A set of opiate-dependent rats received unilateral intra-LC inf usions of Rp-cAMPS ( $40 \mathrm{nmol}$ in $0.5 \mu \mathrm{l}$ ), followed by a systemic naloxone injection. The contralateral LCs were infused with PBS vehicle. Rats were analyzed for tyrosine hydroxylase phosphorylation by use of a back phosphorylation procedure (see Materials and Methods) 30 min after the Sp-cAMPS or Rp-cAMPS infusions, the time of the documented behavioral effects of these agents. Back phosphorylation provides a measure of the dephospho form of a protein, because only sites that are not already phosphorylated endogenously can be back-phosphorylated in tissue extracts. As a result, an increase observed in back phosphorylation of a protein in vitro represents a decrease in the state of phosphorylation of that protein in vivo (see Guitart et al., 1990).

As shown in Figure 7, Sp-cAMPS significantly reduced levels of back phosphorylation of tyrosine hydroxylase in the LC of opiate-naive animals. Conversely, Rp-cAMPS significantly increased levels of tyrosine hydroxylase back phosphorylation in opiate-withdrawing animals. Because back phosphorylation provides a mirror image of the phosphorylation state of a protein, these results provide direct biochemical evidence that intra-LC inf usion of Sp-cAMPS stimulates PKA activity in the LC in vivo, whereas intra-LC infusion of Rp-cAMPS exerts the opposite effect.

The $31 \%$ decrease in tyrosine hydroxylase back phosphorylation (i.e., the $31 \%$ increase in phosphorylation state in vivo) elicited by Sp-cAMPS infusion (Fig. 7) is likely to be physiologically significant, because this is approximately the magnitude of the induction of PKA levels seen in the LC after chronic morphine administration (Nestler and Tallman, 1988; Lane-Ladd et al., 1997). Note that levels of tyrosine hydroxylase back phosphorylation in vehicle-infused LCs were more than twofold lower in opiate-withdrawing rats, as compared with opiate-naive rats (see Fig. 7 legend). This is consistent with the robust increase in cAMP-dependent protein phosphorylation known to occur in the LC on precipitation of opiate withdrawal (Guitart et al., 1990, 1992; Rasmussen et al., 1990). Thus, the $92 \%$ increase in tyrosine hydroxylase back phosphorylation (i.e., the $92 \%$ decrease in phosphorylation state in vivo) elicited by Rp-cAMPS infusion in withdrawing animals indicates that Rp-cAMPS is effective at blocking the withdrawal-induced increase in PKA-mediated protein phosphorylation.

\section{DISCUSSION}

This study provides direct support for the hypothesis that the cAMP second messenger and protein phosphorylation pathway in the LC contributes to the role played by this brain region in opiate withdrawal. Specifically, results of the present study show that certain behavioral signs of opiate withdrawal can be attenuated by intra-LC administration of the highly specific PKA inhibitor Rp-cAMPS. Conversely, intra-LC administration of the highly specific PKA activator Sp-cAMPS elicits several withdrawal-like behaviors in opiate-naive animals.

The results with Rp-cAMPS are consistent with those of two 


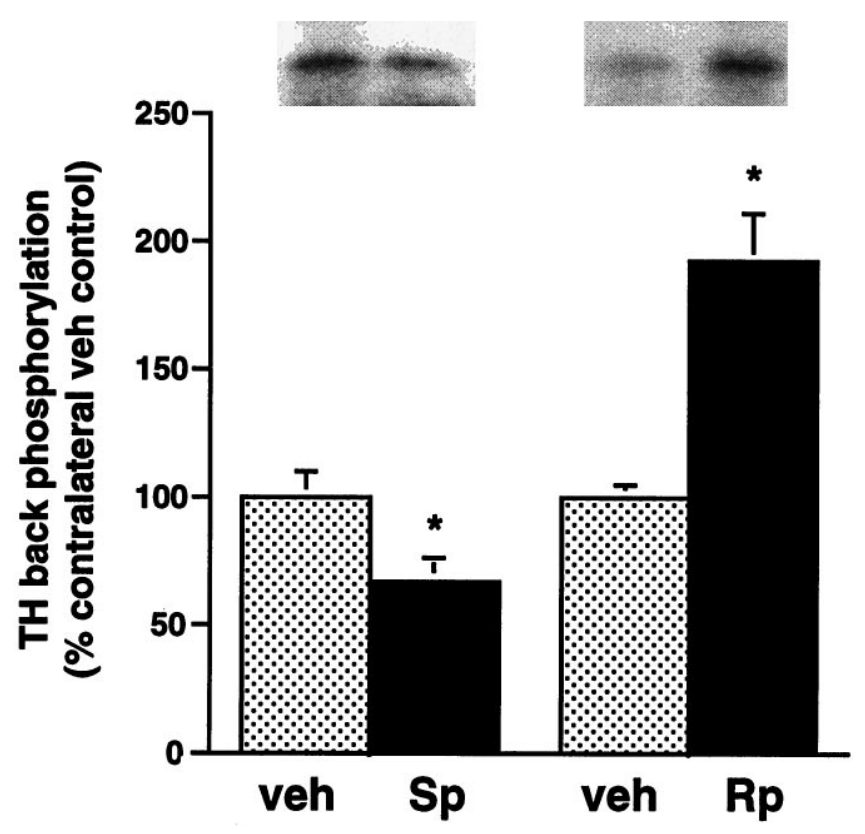

Figure 7. Effect of intra-LC infusion of Sp-cAMPS or Rp-cAMPS on tyrosine hydroxylase back phosphorylation in the LC. Opiate-naive rats received unilateral infusions of Sp-cAMPS (40 nmol in $0.5 \mu \mathrm{l} ; S p$ ); opiate-dependent rats received unilateral infusions of Rp-cAMPS (40 nmol in $0.5 \mu \mathrm{l} ; R p$ ), followed by a systemic injection of naloxone $10 \mathrm{~min}$ later. All contralateral LC's were infused with PBS vehicle (veh). Then the phosphorylation state of tyrosine hydroxylase was determined by back phosphorylation $30 \mathrm{~min}$ after the various infusions (see Materials and Methods). Data are expressed as a percentage of vehicle-infused contralateral control LC $\pm \operatorname{SEM}(n=5)$. Statistically different from PBS ( ${ }^{*} p<0.05$ by $t$ test). Because back phosphorylation provides a measure of the dephospho form of a protein (see Guitart et al., 1990), the Sp-cAMPSinduced decrease in tyrosine hydroxylase back phosphorylation represents an increase in the phosphorylation state of the enzyme in vivo, whereas the Rp-cAMPS-induced increase in tyrosine hydroxylase back phosphorylation represents a decrease in the phosphorylation state of the enzyme in vivo. Note that the level of tyrosine hydroxylase back phosphorylation in the vehicle-infused LC's was reduced in opiatewithdrawing rats, as compared with opiate-naive rats $(40 \pm 2 \% ; n=5$; $p<0.05$ by $t$ test), as illustrated in the representative autoradiograms. This result is consistent with previous findings of a withdrawal-induced increase in PA-mediated protein phosphorylation in the LC (see Guitart et al., 1990, 1992; Rasmussen et al., 1990).

previous studies in which intracerebroventricular or intra-LC infusions of the nonspecific protein kinase inhibitors, $\mathrm{H}-7$ or $\mathrm{H}-8$, which are structurally unrelated to cAMP and inhibit PKA and other kinase activity via a different mechanism, were shown to attenuate opiate withdrawal behaviors (Maldonado et al., 1995; Tokuyama et al., 1995). As seen in the present study with RpcAMPS, the most dramatic effect of the nonspecific protein kinase inhibitors was on several motor-based behaviors. This is consistent with findings of Maldonado et al. (1992), who showed the LC to be particularly important in the regulation of motor signs; infusions of methylnaloxonium, a quarternary ammonium derivative of naloxone, into the LC of opiate-dependent rats produced an especially high level of jumping, rearing, and locomotor activity.

Infusion of Sp-cAMPS into the LC of opiate-naive rats produced a quasi-morphine withdrawal syndrome characterized particularly by explosive locomotor activity, including running and jumping. This is the first demonstration that activation of the cAMP pathway in the LC is sufficient to elicit these types of behaviors. It is noteworthy, however, that intra-LC infusions of Sp-cAMPS in opiate-naive rats failed to elicit wet-dog or head shakes, despite the fact that intra-LC infusions of Rp-cAMPS in rats undergoing opiate withdrawal dramatically attenuated these behaviors. The lack of wet-dog or head shakes in the Sp-cAMPStreated group, along with the absence of grooming, teeth chattering, and digging, may be linked in fact to the extreme level of activity exhibited by these animals, which may have masked the expression of other behaviors.

Our findings with Sp-cAMPS are consistent with earlier work in which several phosphodiesterase inhibitors were shown to produce a quasi-morphine withdrawal syndrome when given systemically to opiate-naive rats. The drugs also exacerbated the severity of opiate withdrawal, particularly motoric behaviors such as jumping (Francis et al. 1975). We similarly found that intra-LC infusion of Sp-cAMPS exacerbates naloxone-precipitated opiate withdrawal but did not characterize this response further because of the distress of the animals at this dose (our unpublished observations). Together, our data provide evidence that the ability of phosphodiesterase inhibitors, which augment the activity of the cAMP pathway by inhibiting the enzymatic breakdown of cAMP, to elicit withdrawal-like behaviors on systemic administration is mediated in part by the LC.

In contrast to our findings in the LC, we found that infusion of Rp-cAMPS into the amygdala had no discernible effect on opiate withdrawal behaviors. This was surprising, given earlier evidence that the amygdala also contributes to physical opiate withdrawal (Maldonado et al., 1992). Moreover, administration of clonidine, an $\alpha_{2}$-adrenergic agonist, either systemically or directly into the amygdala has been shown to attenuate activation of amygdaloid neurons elicited on opiate withdrawal (Freedman and Aghajanian, 1985), similar to the effects of clonidine on LC neurons (Aghajanian, 1978). This effect of clonidine is thought to be attributable to the fact that $\alpha_{2}$-adrenergic receptors and opioid receptors produce their effects on target neurons via a common intracellular cascade involving activation of $\mathrm{G}_{\mathrm{i}} / \mathrm{o}$ G-proteins and inhibition of adenylyl cyclase (Grant and Redmond, 1982; Aghajanian and Wang, 1987; North et al., 1987). Finally, chronic morphine increases levels of PKA activity in the amygdala, although this effect is much smaller than that seen in the LC and is not accompanied by an increase in adenylyl cyclase (Terwilliger et al., 1991). Consistent with the findings of the current study is our previous observation that infusion of clonidine into the amygdala, despite its effects on amygdala neuronal activity, has minimal effects on opiate withdrawal behaviors, whereas its infusion into the LC results in a clear diminution of withdrawal (Taylor et al., $1988,1997)$. One possible explanation for our findings is that the amygdala may contribute to other behavioral aspects of opiate withdrawal (e.g., aversion) that are beyond physical signs monitored in these various studies (see Koob, 1996).

The present study also provides compelling evidence for the involvement of the PAG in the generation of physical opiate withdrawal. As observed for the LC, administration of RpcAMPS into the PAG attenuated opiate withdrawal behaviors, whereas administration of Sp-cAMPS into the PAG elicited certain withdrawal-like behaviors in opiate-naive animals. Interestingly, infusion of these cAMP analogs into the LC and PAG tended to affect a different set of behaviors. This is consistent with results of an earlier study (Maldonado et al., 1995), which compared the effects of intra-LC and intra-PAG infusions of the nonspecific protein kinase inhibitor $\mathrm{H}-7$ on opiate withdrawal. These findings support the view that these two brain regions 
subserve the generation of different withdrawal behaviors, based on their distinct afferent and efferent connections. The findings also raise the possibility that adaptations in the cAMP pathway in the PAG could contribute to the role this region plays in behavioral manifestations of opiate withdrawal. Although initial studies failed to detect increased levels of adenylyl cyclase or PKA in microdissections of the dorsal raphe (a subregion of the PAG) (Duman et al., 1988; Nestler and Tallman, 1988), more recent electrophysiological and biochemical findings have suggested a role for the cAMP system in the chronic actions of opiates in other PAG regions (Jolas and Aghajanian, 1997; S. Lane and E. J. Nestler, unpublished observations).

The importance of the LC in opiate withdrawal has been questioned by some authors (Christie et al., 1997), who suggest that the ability of agents administered directly into the LC to affect withdrawal is attributable to diffusion of the agents to neighboring regions, such as the PAG. However, the findings that intra-LC and intra-PAG infusions of Rp-cAMPS, Sp-cAMPS, or $\mathrm{H}-7$ elicit a distinct subset of behaviors argue against this interpretation. Moreover, if intra-LC infusions produced behavioral effects via diffusion to the PAG, then one would expect lower doses of drug to be effective in the PAG, which was not the case for Rp-cAMPS in the present study or for methylnaloxonium in a previous study (Maldonado et al., 1992).

The effects of Rp-cAMPS and Sp-cAMPS observed in the present study do not appear to be the result of neurotoxicity. Because Rp-cAMPS and Sp-cAMPS are stereoisomers of each other, any such effects would be expected to be similar. Furthermore, our finding that no scarring, gliosis, or other tissue abnormality was detectable at the infusion sites suggests that there was no toxicity associated with these compounds. Possible effects at adenosine receptors are also unlikely because the cAMP analogs are highly resistant to degradation, and their degradation would generate equivalent adenosine derivatives. Findings cited above with H-7 (Maldonado et al., 1995; Tokuyama et al., 1995), which is an isoquinoline protein kinase inhibitor that would not affect adenosine receptors, further support this interpretation. Thus, the opposite behavioral effects of the cAMP analogs are most likely attributable to their opposite modulation of PKA activity, which was documented directly in this study by measures of the in vivo phosphorylation state of tyrosine hydroxylase in the LC. The use of Rp-cAMPS and Sp-cAMPS as an inhibitor and activator, respectively, of the cAMP pathway on intracerebral administration is supported further by a recent study that found opposite effects of these cAMP analogs in the nucleus accumbens on cocaine self-administration (Self and Nestler, 1995). In that study the effects of Rp-cAMPS and Sp-cAMPS infusions also were found to produce opposite changes in CREB and DARPP-32 phosphorylation, again demonstrating that intracerebral infusions of these analogs effectively can modulate intracellular PKA activity in vivo.

These data provide behavioral evidence in support of the hypothesis that physical opiate withdrawal is mediated in part by increased PKA activity in the LC and other brain regions such as the PAG. The mechanism by which long-term exposure to morphine upregulates the cAMP pathway in subpopulations of opiate-responsive neurons is unknown, but our behavioral results emphasize the significance of these neuroadaptations in opiate dependence.

\section{REFERENCES}

Aghajanian GK (1978) Tolerance to locus coeruleus neurons to morphine and suppression of withdrawal response by clonidine. Nature 267:186-188.

Aghajanian GK, Wang YY (1987) Common alpha-2 and opiate effector mechanisms in the locus coeruleus: intracellular studies in brain slices. Neuropharmacology 26:789-800.

Akaoka A, Aston-Jones G (1991) Opiate withdrawal-induced hyperactivity of locus coeruleus neurons is substantially mediated by augmented excitatory amino acid input. J Neurosci 11:3830-3839.

Alreja M, Aghajanian GK (1991) Pacemaker activity of locus coeruleus neurons: whole-cell recordings in brain slices show dependence on cAMP and protein kinase A. Brain Res 556:339-343.

Blasig J, Reinhold HK, Zieglgansberger S (1973) Development of physical dependence on morphine in respect to time and dosage and quantification of the precipitated withdrawal syndrome in rats. Psychopharmacologia (Berl) 33:19-38.

Calvino B, Lagowska J, Ben-Ari Y (1979) Morphine withdrawal syndrome: differential participation of structures located within the amygdaloid complex and striatum of the rat. Brain Res 177:19-34.

Christie MJ, Williams JT, Osborne PB, Bellchambers CE (1997) Where is the locus in opioid withdrawal? Trends Pharmacol Sci 18:134-140.

Cools AR, Ellenbroek BA, Van Den Heuvel CM (1983) Picrotoxin microinjection into the brain: a model of abrupt withdrawal "jumping" behavior in rats not exposed to any opiate? Eur $\mathrm{J}$ Pharmacol 90:237-243.

Duman RS, Tallman JF, Nestler EJ (1988) Acute and chronic opiate regulation of adenylate cyclase in brain: specific effects in locus coeruleus. J Pharmacol Exp Ther 246:1033-1039.

Francis DL, Roy AC, Collier H (1975) Morphine abstinence and quasiabstinence effects after phosphodiesterase inhibitors and naloxone. Life Sci 16:1901-1906.

Freedman JE, Aghajanian GK (1985) Opiate and alpha-2-adrenoceptor responses of rat amygdaloid neurons: colocalization and interactions during withdrawal. J Neurosci 5:3016-3024.

Gjertsen BT, Mellgren G, Otten A, Maronde E, Genieser H-G, Jastorff B, Vintermyr OK, McKnight GS, Doeskeland SO (1995) Novel (Rp)cAMPS analogs as tools for inhibition of cAMP-kinase in cell culture. Basal cAMP-kinase activity modulates interleukin-1 beta action. J Biol Chem 270:20599-20607.

Grant SJ, Redmond DE (1982) Methylxanthine activation of noradrenergic unit activity and reversal by clonidine. Eur $\mathrm{J}$ Pharmacol 85:105-109.

Guitart X, Nestler EJ (1989) Identification of morphine- and cyclic AMP-regulated phosphoproteins (MARPPs) in the locus coeruleus and other regions of rat brain: regulation by acute and chronic morphine. J Neurosci 9:4371-4387.

Guitart X, Hayward M, Nisenbaum LK, Beitner DB, Haycock JW, Nestler EJ (1990) Identification of MARPP-58, a morphine- and cyclic AMP-regulated phosphoprotein of $58 \mathrm{kDs}$, as tyrosine hydroxylase: evidence for regulation of its expression by chronic morphine in the rat locus coeruleus. J Neurosci 10:2635-2645.

Guitart X, Thompson MA, Mirante CK, Greenberg ME, Nestler EJ (1992) Regulation of CREB phosphorylation by acute and chronic morphine in the rat locus coeruleus. J Neurochem 58:1168-1171.

Jolas T, Aghajanian GK (1997) Opioids suppress spontaneous and NMDA-induced inhibitory postsynaptic currents in the dorsal raphe nucleus of the rat in vitro. Brain Res 755:229-245.

Kogan JH, Nestler EJ, Aghajanian GK (1992) Elevated basal firing rates of locus coeruleus neurons in brain slices from opiate-dependent rats: association with enhanced responses to 8-Br-cAMP. Eur J Pharmacol 211:47-53.

Koob GF (1996) Drug addiction: the yin and yang of hedonic homeostasis. Neuron 16:893-896.

Koob GF, Maldonado R, Stinus L (1992) Neural substrates of opiate withdrawal. Trends Neurosci 15:186-191.

Lagowska J, Calvino B, Ben-Ari Y (1978) Intra-amygdaloid applications of naloxone elicits severe withdrawal signs in morphine-dependent rats. Neurosci Lett 8:241-245.

Lane-Ladd SB, Pineda J, Boundy V, Pfeuffer T, Krupinski J, Aghajanian GK, Nestler EJ (1997) CREB in the locus coeruleus: biochemical, physiological, and behavioral evidence for a role in opiate dependence. J Neurosci 17:7890-7901.

Maldonado R, Koob GF (1993) Destruction of the locus coeruleus decreases physical signs of opiate withdrawal. Brain Res 605:128-138. 
Maldonado R, Stinus L, Gold L, Koob G (1992) Role of different brain structures in the expression of the physical morphine withdrawal syndrome. J Pharmacol Exp Ther 261:669-677.

Maldonado R, Valverde O, Garbay C, Roques BP (1995) Protein kinases in the locus coeruleus and periaqueductal gray matter are involved in the expression of opiate withdrawal. Naunyn Schmiedebergs Arch Pharmacol 352:565-575.

Maldonado R, Blendy JA, Tzavara E, Gass P, Roques BP, Hanoune J (1996) Reduction of morphine abstinence in mice with a mutation in the gene encoding CREB. Science 273:657-659.

Matsuoka I, Maldonado R, Defer N, Noel F, Hanoune J, Roques BP (1994) Chronic morphine administration causes region-specific increase of brain type VIII adenylyl cyclase mRNA. Eur J Pharmacol 268:215-221.

Nestler EJ (1992) Molecular mechanisms of drug addiction. J Neurosci $12: 2439-2450$.

Nestler EJ (1996) Under seige: the brain on opiates. Neuron 16:897-900.

Nestler EJ, Tallman JF (1988) Chronic morphine treatment increases cyclic AMP-dependent protein kinase activity in the rat locus coeruleus. Mol Pharmacol 33:127-132.

North RA, Williams JT, Surprenant A, Christie MJ (1987) $\mu$ and $\delta$ receptors both belong to a family of receptors which couple to a potassium conductance. Proc Natl Acad Sci USA 84:5487-5491.

Paxinos G, Watson C (1982) The rat brain in streotaxic coordinates. New York: Academic.

Rasmussen K, Aghajanian GK (1989) Withdrawal-induced activation of locus coeruleus neurons in opiate-dependent rats: attenuation by lesions of the nucleus paragigantocellularis. Brain Res 505:346-350.

Rasmussen K, Beitner DB, Krystal JH, Aghajanian GK, Nestler EJ
(1990) Opiate withdrawal and the rat locus coeruleus: behavioral, electrophysiological, and biochemical correlates. J Neurosci 10:2308-2317.

Rasmussen K, Brodsky M, Inturrisi CE (1995) NMDA antagonists and clonidine block $c$-fos expression during morphine withdrawal. Synapse 20:68-74.

Self DW, Nestler EJ (1995) Molecular mechanisms of drug reinforcement and addiction. Annu Rev Neurosci 18:463-495.

Shiekhattar R, Aston-Jones G (1993) Modulation of opiate responses in brain noradrenergic neurons by the cyclic AMP cascade: changes with chronic morphine. Neuroscience 57:879-885.

Taylor JR, Elsworth JD, Garcia EJ, Grant SJ, Roth RH, Redmond Jr DE (1988) Clonidine infusions into the locus coeruleus attenuate behavioral and neurochemical changes associated with naloxone-precipitated withdrawal. Psychopharmacology 96:121-134.

Taylor JR, Punch L, Elsworth JD (1997) A comparison of the effects of clonidine and CNQX infusion into the LC and the amygdala on naloxone-precipitated opiate withdrawal. Psychopharmacology, in press.

Terwilliger RZ, Beitner-Johnson D, Sevarino KA, Crain SM, Nestler EJ (1991) A general role for adaptations in G-proteins and the cyclic AMP system in mediating the chronic actions of morphine and cocaine on neuronal function. Brain Res 548:100-110.

Tokuyama S, Feng Y, Wakabayashi H, Ho I (1995) Possible involvement of protein kinases in physical dependence on opioids: studies using protein kinase inhibitors H-7 and H-8. Eur J Pharmacol 284:101-107.

Wolf G (1971) Elementary histology for neuropsychologists. In: Methods in psychobiology, Vol 1 (Myers RD, ed), pp 281-300. London: Academic. 